\title{
Slow slip in the focal region of the anticipated Tokai earthquake following the seismo-volcanic event in the northern Izu Islands in 2000
}

\author{
Akio Kobayashi ${ }^{1}$, Akio Yoshida ${ }^{2}$, Takeyasu Yamamoto ${ }^{1}$, and Hiromi Takayama ${ }^{1}$ \\ ${ }^{1}$ Meteorological Research Institute, 1-1 Nagamine, Tsukuba-shi, Ibaraki-ken 305-0052, Japan \\ ${ }^{2}$ Tokyo District Meteorological Observatory, Otemachi 1-3-4, Chiyoda-ku, Tokyo 100-0004, Japan
}

(Received August 25, 2004; Revised February 16, 2005; Accepted April 8, 2005)

\begin{abstract}
Transient crustal deformation occurred in the regions of Kanto and Tokai during the seismo-volcanic event in the northern Izu Islands in 2000. In our investigation of the observed deformation, we constructed an optimumsource model of the event between Miyake and Kozu Islands. We then made an inversion analysis of the differences between the observed displacement field and the calculated displacement field from the optimum model, assuming that the differences were caused by the changes in the interplate coupling beneath the Tokai region. From the inversion analysis of data for each of three-month periods, May to August, June to September, and July to October, we found decreased interplate coupling in the early stages of the 2000 event. In the first stage, either a slow slip or a temporary suspension of the plate subduction occurred in the focal region of the anticipated Tokai earthquake. The area then extended to the west and, finally, a slow slip exceeded the secular convergence velocity on the plate interface near Lake Hamana in the fall of 2000. We believe this ongoing slow slip began in August or early September 2000.
\end{abstract}

Key words: Tokai region, slow slip, interplate coupling, crustal deformation.

\section{Introduction}

A huge swarm activity including five earthquakes of magnitude 6 or greater occurred in the summer of 2000 in the sea region between Miyake and Kozu Islands, south of the Izu Peninsula of central Japan (Fig. 1, Japan Meteorological Agency [JMA] 2000). The magma, which rose beneath the volcano on Miyake Island on 26 June, flowed into a northwest-striking dyke that intruded into the upper crust in the direction of Kozu Island (Sasai et al., 2002; Furuya et al., 2003). The dyke formation generated the swarm activity in the sea region (Sakai et al., 2001), and its most active period ended in mid-August. The volcano on Miyake Island, after repeated summit eruptions, discharged a great deal of volcanic gas, beginning in September and continuing through the summer of 2004. In the following work, we refer to this enormous seismo-volcanic activity as the 2000 northern Izu Islands event or, simply, the 2000 event.

The continuous global positioning system (GPS) observation network (GEONET; e.g., Miyazaki et al., 1998) of the Geographical Survey Institute (GSI) of Japan revealed that a remarkable crustal deformation occurred over a broad area, from the Boso Peninsula to the Tokai district along the Pacific coast of Japan during the 2000 event (Kaidzu et al., 2000; Kobayashi et al., 2003). Nishimura et al. (2001) and Ozawa et al. (2004) proposed source models to account for the notable displacement fields around the northern Izu Islands during the most active period (from June to August 2000). These models consisted of tensile faults representing

Copy right(c) The Society of Geomagnetism and Earth, Planetary and Space Sciences (SGEPSS); The Seismological Society of Japan; The Volcanological Society of Japan; The Geodetic Society of Japan; The Japanese Society for Planetary Sciences; TERRAPUB. the dyke intrusion, large earthquake faults, and aseismicshear faults. Even though there was no direct evidence to support its existence, they incorporated an east-west striking aseismic-shear fault in the source model to explain surplus eastward displacements that could not be modeled by the dyke and earthquake faults. Kobayashi et al. (2003) determined the optimum source parameters of the displacement fields for each three-month period, May to August, June to September, and July to October, based on a similar model with GPS data from a broader area, from the Kanto to Tokai regions. They demonstrated that although the optimum source model could represent the major parts of the crustal deformation for each of the three-month periods, they could not explain the noticeable eastward (June to September) and southward (July to October) displacements observed in the Tokai and surrounding regions. They suggested that an inelastic diffusion of strain might have caused the unexplained displacements, including the migration of the source region. In this paper we propose a new explanation of the enigmatic displacement fields in Tokai and its circumferential areas in the later periods of the 2000 event.

\section{Data}

We used the GPS coordinate data processed by GSI and described by Hatanaka et al. (2003) to re-examine crustal deformation for each of the three-month periods, May to August, June to September, and July to October of 2000. We defined the displacement for each period as the difference of the averages of the coordinate values for the first and last months of that period. Because the displacement field in the Kanto and Tokai regions is substantially influenced by the subduction of the Philippine Sea and Pacific plates, 


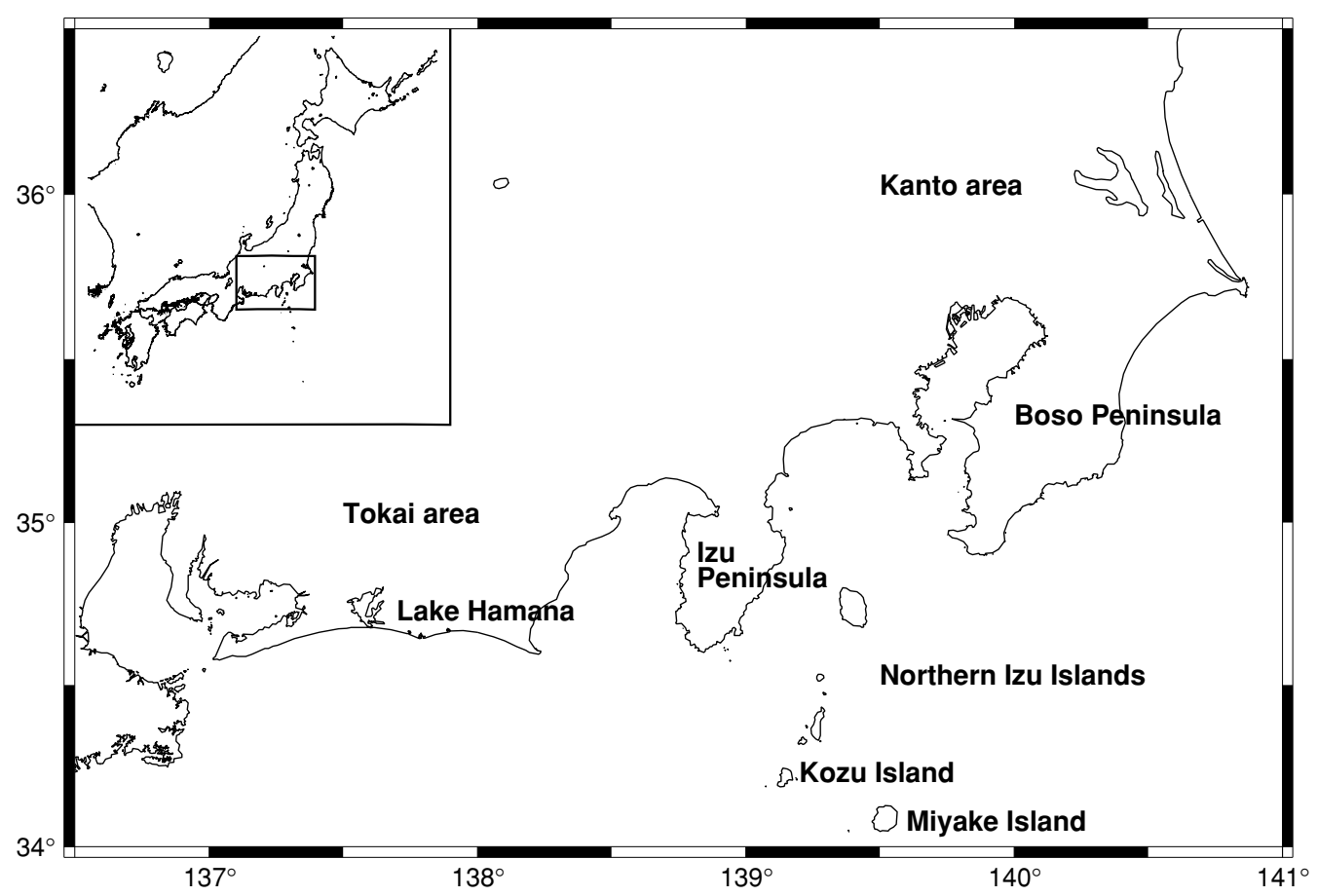

Fig. 1. Map of Kanto and Tokai regions.

we had to be careful in examining crustal deformation produced by the 2000 event solely on the basis of the GPS data. We attempted to isolate the deformation caused by the 2000 event by subtracting the average velocity of the horizontal displacement measured at each GPS station during the period of January 1998 through December 1999 from the total velocity. According to Kaidzu (2003), the velocity field just before the 2000 event represents the secular change. Figure 2 displays the raw displacements in 2000 and the corrected displacements determined by subtracting those average velocity measurements. We adopted the Ohgata station (Fig. 2) as a fixed point of the displacement field because it was not influenced by the crustal deformation of the 2000 event.

The coordinate data of the GEONET contained apparent annual and semi-annual variations (Murakami and Miyazaki, 2001), and removal of the average velocity field per year was therefore not enough to enable investigation of the transient displacements over several months. Yamamoto (2002) demonstrated that systematic changes of amplitude and phase in the annual variation of the GEONET data in 2000 could cause significant errors if we applied the amplitude and phase derived from the data before 2000 to the data after 2000 before subtracting the annual variations. We introduced the formula shown in Eq. (1) that represents the annual and semi-annual variations of each vector component for every GEONET station for the periods before and after the 2000 event, i.e., (a) January 1998 to December 1999 and (b) January 2001 to December 2002.

$$
\begin{aligned}
y= & c_{1} t+c_{2} t^{2}+c_{3} \sin (2 t)+c_{4} \cos (2 t) \\
& +c_{5} \sin (4 t)+c_{6} \cos (4 t)+c_{7} .
\end{aligned}
$$

Here, $y$ represents the corrected displacement and $t$ represents the time of year. To determine the annual and semi-annual variations, we estimated the coefficients $c_{1}, c_{2}, \ldots, c_{7}$ from the data of the former period (a), applying it to the data before May 2000, and used the formula on data from the latter period (b), applying it to the data after June 2000.

We averaged and gridded the displacements at GPS stations at 0.5 degrees, smoothed them with a spline function, and depicted the spatially continuous displacement field from the grid data using a GMT tool (Wessel and Smith, 1995). In making the map, we did not use the displacements at stations in the northern Izu Islands because they were too large in comparison to those of other stations. Kobayashi et al. (2003) used the same procedure except without the data from the GPS stations in the Izu Peninsula, which we included in our study.

Figure 3 depicts the transient displacement fields for each of the three-month periods, May to August (top), June to September (middle), and July to October (bottom), in 2000, demonstrating the conspicuous northeastward movement in Kanto and southeastward movement in Tokai. Note that the southeastward movement area in Tokai later extended significantly to the west and north. We did not observe a similar expansion in the northeastward displacement area in Kanto; rather, the affected area decreased from July to October. The difference in the temporal evolutions is significant for the displacement field between Tokai and Kanto, implying that the crustal deformation in the Tokai and Kanto regions cannot be explained only in terms of the sources of the 2000 event.

\section{Analysis}

\subsection{Source modeling}

We first attempted to create an optimum source model to explain the crustal deformation during each of the three- 

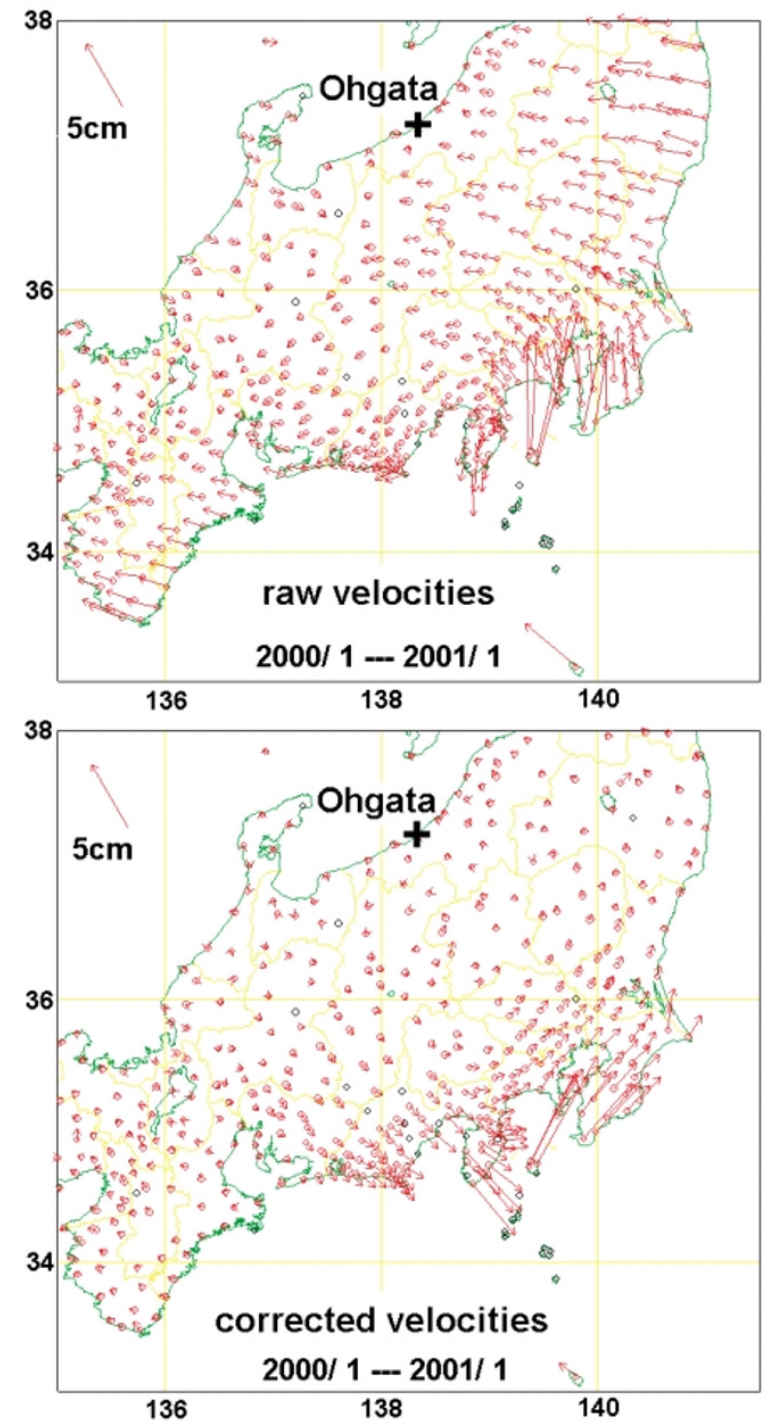

Fig. 2. Raw displacements at GPS stations relative to that at Ohgata (+ mark) in 2000 (upper) and the corrected displacements where velocities from 1998 to 1999 were subtracted (lower).

month periods. We used a source model similar to that in Kobayashi et al. (2003). Figure 4 shows the model consisting of a dyke, earthquakes, and a creep-like shear fault in the sea region between Miyake and Kozu Islands. Table 1 presents the hypocenters and mechanisms of five earthquakes with magnitude greater than 6.0 taken from the JMA data. We based the source dimensions and strike directions of the dyke and the creep-like shear fault on the source area of the swarm activity. In our nonlinear inversion analysis, we used an algorithm provided by Matsu'ura and Hasegawa (1987) and horizontal displacements from 54 GPS stations in Kanto, Chubu and Tokai (Fig. 4). Although vertical displacements sometimes play a critical role in estimating the source parameters of crustal deformation, we did not use them because the observed vertical displacements during the 2000 event were close to the noise level, less than $1 \mathrm{~cm}$. This was consistent with the fact that the supposed sources, composed of a vertical dyke and strike slip faults, would not produce a significant up-down movement. Table 2 shows the optimal parameters for the open-
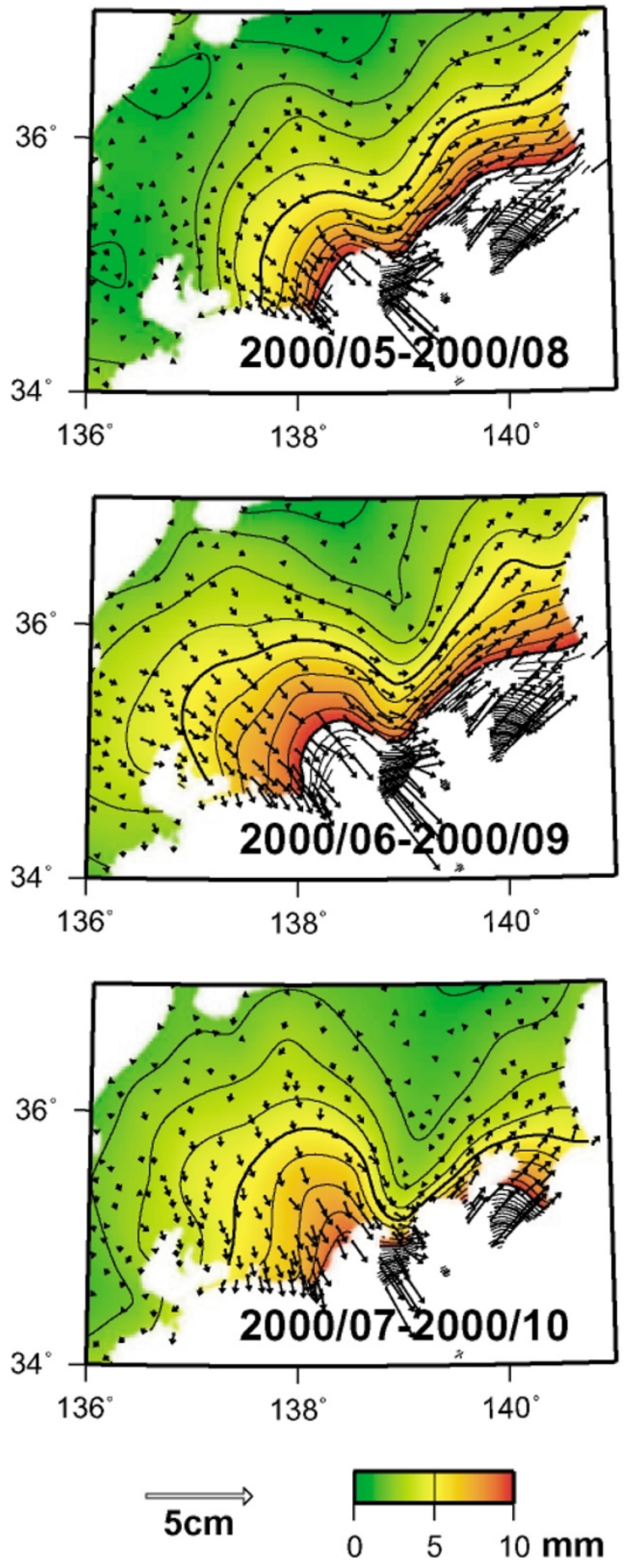

Fig. 3. Displacements for each three-month periods, May to August (top), June to September (middle), and July to October (bottom), in 2000. We subtracted the average rate for January 1997 through January 2000 to determine the unsteady deformation due to the 2000 seismo-volcanic event in the northern Izu Islands.

ing of the dyke and the slip on the creep-like shear fault for each period. Ozawa et al. (2004) examined the time evolution of the source model consisting of a dyke, a left-lateral creep-like fault off the west coast of Miyake Island, and a right-lateral creep-like fault off the east coast of Kozu Island. Their results, with a greater slip on the right-lateral fault from mid July to early August, were consistent with our results. 

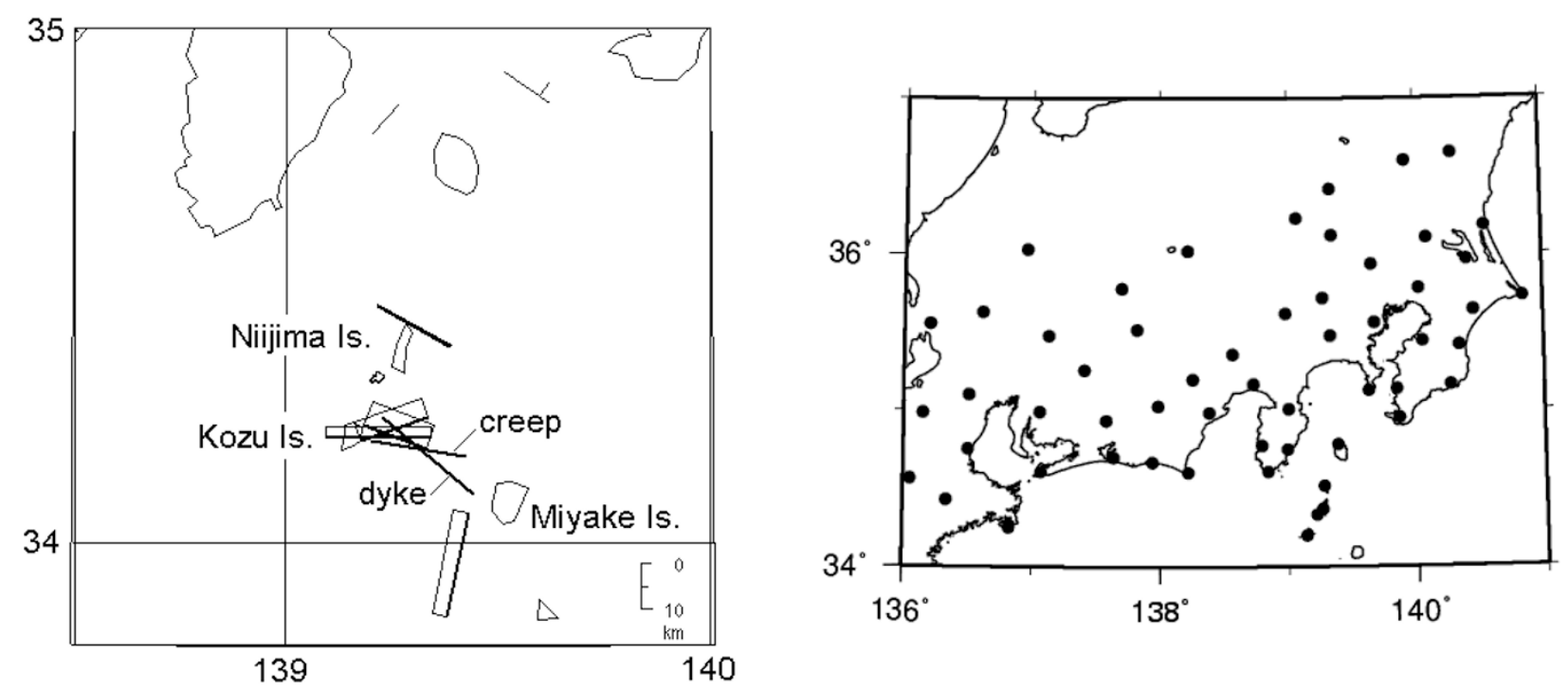

Fig. 4. Left: Locations of a dyke, five earthquakes of M6 or greater, and a creep-like shear fault that were considered to be the source for the crustal deformation during the 2000 northern Izu Islands event. Right: Location of the GPS stations used in the inversion analysis.

Table 1. Fixed parameters of sources used in the inversion analysis.

\begin{tabular}{lccccccccc}
\hline \multicolumn{1}{c}{ Sources } & $\begin{array}{c}\text { Lat. } \\
{ }^{\circ} \mathrm{N}\end{array}$ & $\begin{array}{c}\text { Long. } \\
{ }^{\circ} \mathrm{E}\end{array}$ & $\begin{array}{c}\text { Depth } \\
\mathrm{km}\end{array}$ & $\begin{array}{c}\text { Length } \\
\mathrm{km}\end{array}$ & $\begin{array}{c}\text { Width } \\
\mathrm{km}\end{array}$ & $\begin{array}{c}\text { Strike } \\
\text { deg. }\end{array}$ & $\begin{array}{c}\text { Dip } \\
\text { deg. }\end{array}$ & $\begin{array}{c}\text { Rake } \\
\text { deg. }\end{array}$ & $\begin{array}{c}\text { Slip } \\
\mathrm{mm}\end{array}$ \\
\hline Dyke & 34.245 & 139.225 & 5.0 & 25.0 & 10.0 & 130 & 90 & - & - \\
Creep-like fault & 34.200 & 139.200 & 5.0 & 20.0 & 10.0 & 100 & 90 & -180 & - \\
2000/7/1 16:01 M6.4 & 34.205 & 139.222 & 10.0 & 22.0 & 11.0 & 270 & 77 & -163 & 700 \\
2000/7/9 03:57 M6.1 & 34.223 & 139.254 & 8.0 & 15.0 & 7.8 & 251 & 59 & 176 & 490 \\
2000/7/15 10:30 M6.2 & 34.418 & 139.248 & 4.0 & 17.4 & 8.7 & 299 & 87 & -148 & 550 \\
2000/7/30 21:25 M6.4 & 33.962 & 139.400 & 12.0 & 22.0 & 11.0 & 286 & 79 & -164 & 690 \\
2000/8/18 10:52 M6.0 & 34.208 & 139.257 & 8.0 & 13.8 & 6.9 & 291 & 39 & -125 & 437 \\
\hline
\end{tabular}

Table 2. Optimum values for the parameters of the dyke and the creep-like shear fault determined by inversion analysis.

\begin{tabular}{lccc}
\hline \multicolumn{1}{c}{ Period } & $05-08$ & $06-09$ & $07-10$ \\
\hline Opening of the dyke $(\mathrm{m})$ & $2.80 \pm 0.04$ & $2.70 \pm 0.04$ & $1.69 \pm 0.04$ \\
Dislocation on the right-lateral creep-like fault $(\mathrm{m})$ & $1.66 \pm 0.05$ & $2.34 \pm 0.05$ & $2.10 \pm 0.05$ \\
\hline
\end{tabular}

Although the optimum source model accounted for the crustal deformations that were fairly consistent in all time periods, it could not explain the temporal change in spatial deformation patterns in the Tokai and Kanto regions. Figure 5 illustrates the distribution of residuals between the observed displacements and those calculated from the optimal model. Note that the residuals were dominant in Tokai and the surrounding regions from June to September and from July to October. In the Kanto region, the difference was less evident but still detectable.

\subsection{Slow slip estimation}

Kobayashi et al. (2003) noted that the residual southward displacements in the Tokai and surrounding regions from July to October did not depend much on the distance from the sea coast. This implied that an additional source for the deformation should be located farther away than the northern Izu Islands area, and that it had a strong directivity because the southward displacement was observed only in Tokai and to the north. An apparent expansion of the area where the southward displacements were observed, also suggested that the location of the additional source might have moved. To understand the enigmatic displacement field in Tokai, Kobayashi et al. (2003) proposed that strain might have diffused through a visco-elastic process in a two-layer system consisting of an elastic crust and a ductile mantle. However, a quantitative evaluation of the process and a specification of the additional source were left as future problems.

We propose a different hypothesis to interpret this displacement field. A key concept of this idea is slow slip in and around the focal region of the anticipated Tokai earthquake. To determine the distribution of slow slip on the plate interface beneath the Tokai region, we performed inversion analyses using the residual displacement fields 

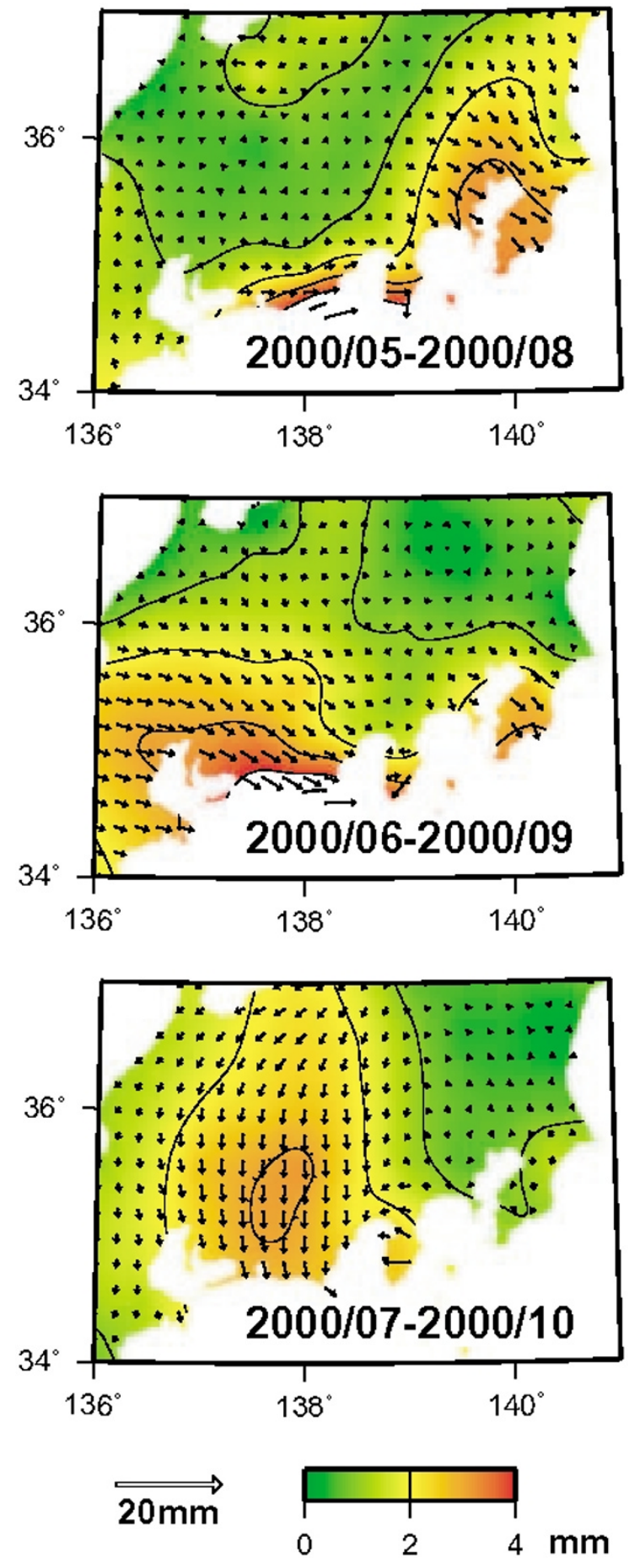

Fig. 5. Difference between the observed displacement field and the displacement calculated from the optimum model shown in Fig. 4. Each panel corresponds to that in Fig. 3 .

shown in Fig. 5 and the method originally used by Yabuki and Matsu'ura (1992).

We can explain interplate coupling by superposing an imaginary, normal backward slip (back slip, or the deficit of a relative forward slip between overriding and subducting plates) on the steady-state subduction (Savage, 1983). In this paper, 'normal slip' stands for the slip against the subduction of the plate and 'forward slip' indicates the slip due to the subduction. Full coupling occurs when the magnitude of the back-slip rate equals the subduction velocity in the steady state. We define the slow slip as the decrease of back slip that had occurred in the period before the 2000 event. Figure 6 depicts the distribution of back-slip velocity from January 1997 through December 1999, as estimated by the displacements at 58 GPS stations. The left panel of Fig. 6 shows the locations of those stations, as well as the equi-depth contour lines. The plate configuration used here is the same as that used by Sagiya (1999). Arrows in the right panel of Fig. 6 indicate the slip vectors of the overriding continental plate in relation to the subducting Philippine Sea plate. If the back-slip rate were equal to the subduction rate, that is, if the magnitude of the slip vector in Fig. 6 were equal to that of the relative plate velocity, full coupling would occur. Maps in Fig. 7 depict the slip distributions on the plate interface, as estimated by the residual displacement fields in Fig. 5, for each three-month period. We used relative displacement vectors at intervals of 0.2 degrees for our inversion analysis, performed between 34.6 and 36.0 degrees north and between 136.6 and 138.4 degrees east. The standard deviation in the estimation of the slip was 2 to $3 \mathrm{~cm}$ per year for these periods. We must pay particular attention to the feature that the direction of the arrows in the maps in Fig. 7 are southeastward, which does not necessarily mean that a forward slip, that exceeded the secular convergence rate, occurred. We should note here that arrows in the direction opposite to the back-slips (right panel of Fig. 6) indicate difference of back-slips in those periods from back-slips in the steady-state. To ascertain that the slow slip in Fig. 7 was not artificial, we applied the same inversion method to the data of the three-month periods preceding the 2000 event. For most of the periods, the estimated slips on the plate interface were less than $1 \mathrm{~cm}$. Though slips of several centimeters were estimated for a few periods, these values were one to two times the estimation errors. In contrast, the estimated slips during the 2000 event were five to eight times the estimation error.

\section{Discussion}

In the map for May to August 2000 (Fig. 7), eastward slips occurred in the southeastern part of the focal region of the anticipated Tokai earthquake (the area within the closed curve in Fig. 7). Although the slips at some grid points seem to exceed magnitudes of the secular back-slip rates, they actually show that almost complete slipping occurs in the relative motion between the subducting and overriding plates if we consider the errors in the inversion analysis. It is possible that there was a temporary suspension of the subduction of the Izu microplate (Sagiya, 1999) on the Suruga Trough. For June to September, the magnitude of the slow slip rate at many grids along the western and northern boundary of the focal region of the Tokai earthquake exceeded the secular-plate convergence rate. The slow slip beneath Lake Hamana and to the northwest became noticeable from July to October, while the interplate coupling in the southern half of the focal region of the Tokai earthquake resumed. We must note that the slip velocity in Fig. 7 was computed from three months of data, and the value shows momentary velocity for the period. These three periods have overlapped each other, and the location of the large slip area is different. As is mentioned above, we can see 


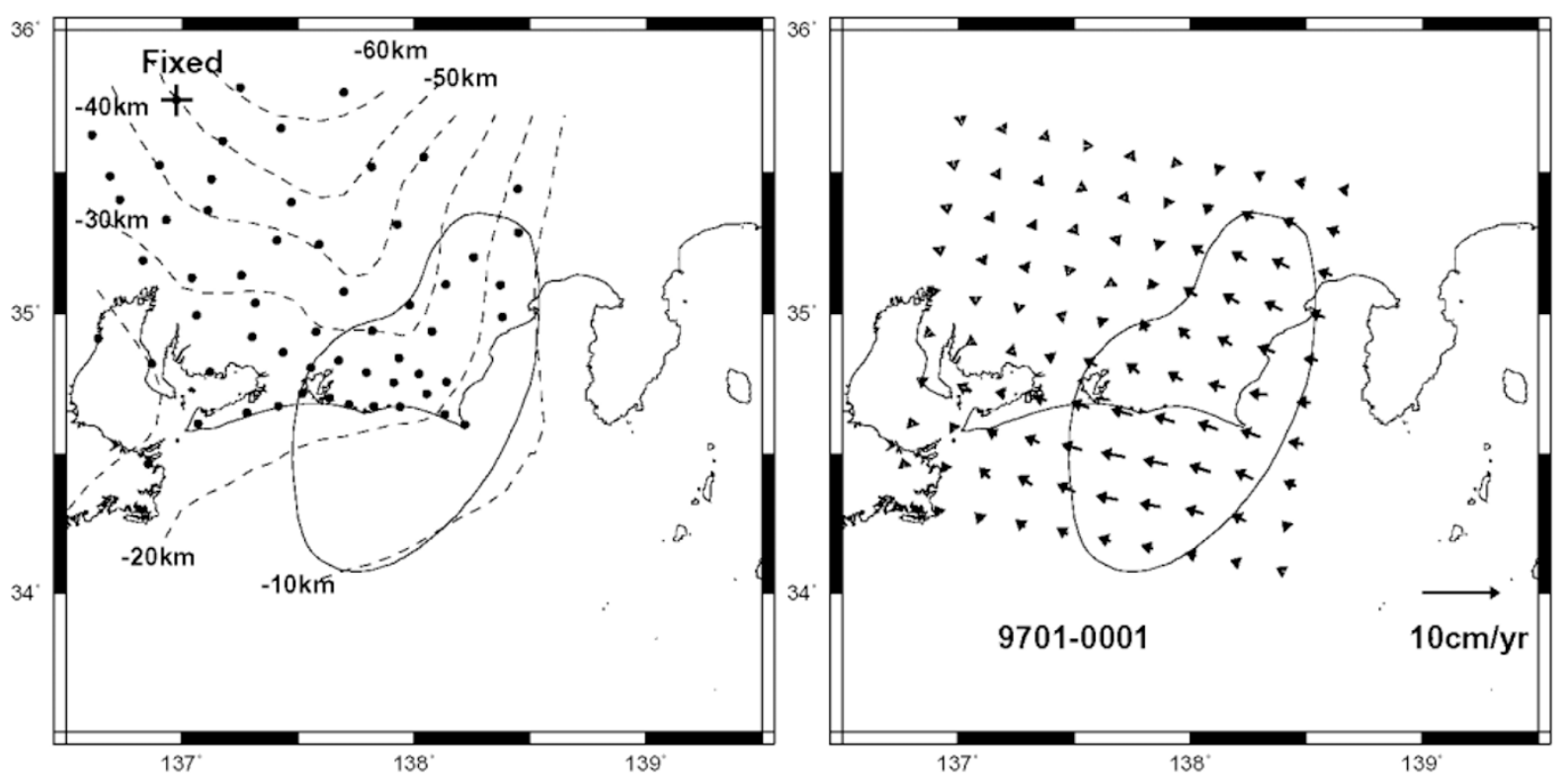

Fig. 6. Left: Equi-depth contours of the subducting Philippine Sea slab and locations of GPS stations whose data were used in the inversion analysis. Right: Back-slip distribution on the plate interface per year from 1997 through 1999.

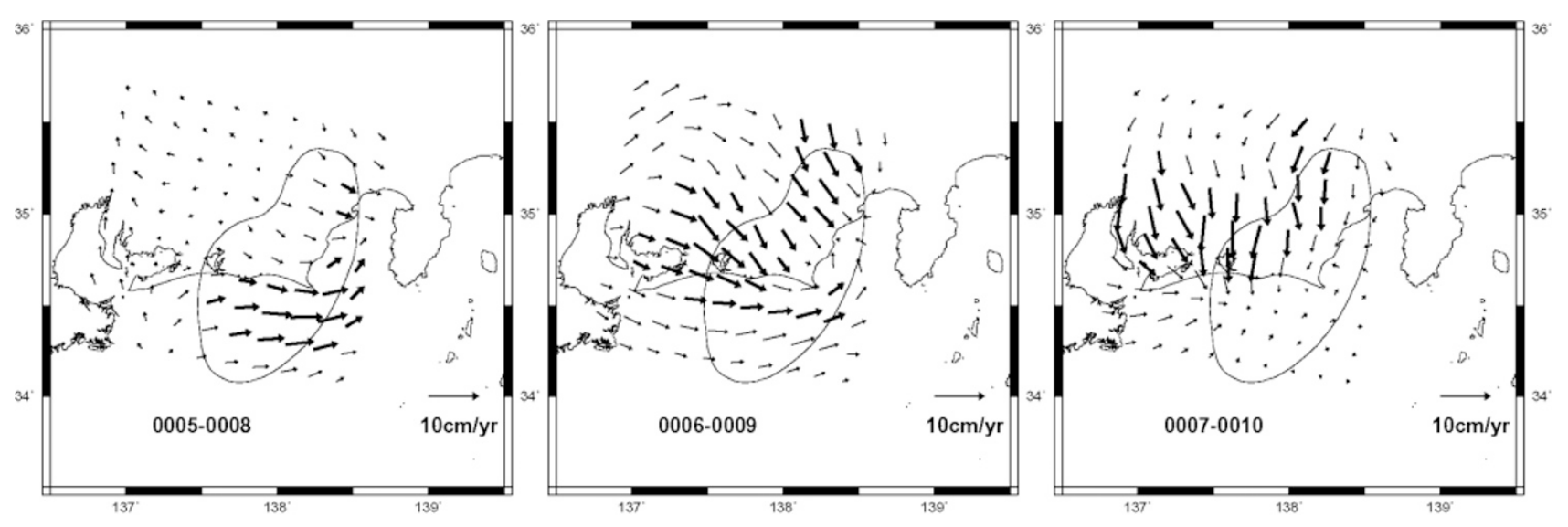

Fig. 7. Slip distribution on the plate interface determined by the inversion analysis using the displacement fields shown in Fig. 5. Left, middle and right panels are for May to August, June to September, and July to October. The thick arrows show that the magnitude of the slip vector is four times larger than its standard deviation.

large slips on the southeastern part of the focal region of the anticipated Tokai earthquake for the period from May to August. Since the slip is not observed in the period from July to October, it seems to have ended by July. We also can see large slips near Lake Hamana and to the northwest region in the period from June to September and from July to October. The slip seems to begin after August, because the slip is not observed in the period from May to August. Though there are some large slips in the northwest part in the calculating area in the period from June to September, the reliability is low, if we consider the ratio between values and errors.

The new source model, which includes slow slips on the plate interface beneath the Tokai region in addition to the dyke, earthquakes, and the creep-like shear fault located to the west of Miyake Island, gives a good explanation of the evolution of the crustal deformation in Tokai and the surrounding regions. Figure 8 demonstrates this and shows the differences between the observed displacement fields and those calculated from the new model. The results, which show that the forward slip exceeds the secular convergence rate from June to September and July to October but did not occur from May to August, suggest that the ongoing Tokai slow event found by Ozawa et al. (2002) had already begun during the second half of the 2000 event (August or early September 2000). Further indication that 'the Tokai slow slip' beneath the Tokai region might have been caused by the 2000 event is that the slow slip first occurred in the southeastern part of the focal region of the anticipated Tokai earthquake, near the northern Izu Islands, and then migrated to the west.

\section{Summary}

We analyzed the temporal evolution of the crustal deformation during the 2000 seismo-volcanic event in northern Izu Islands by considering the change in the interplate cou- 

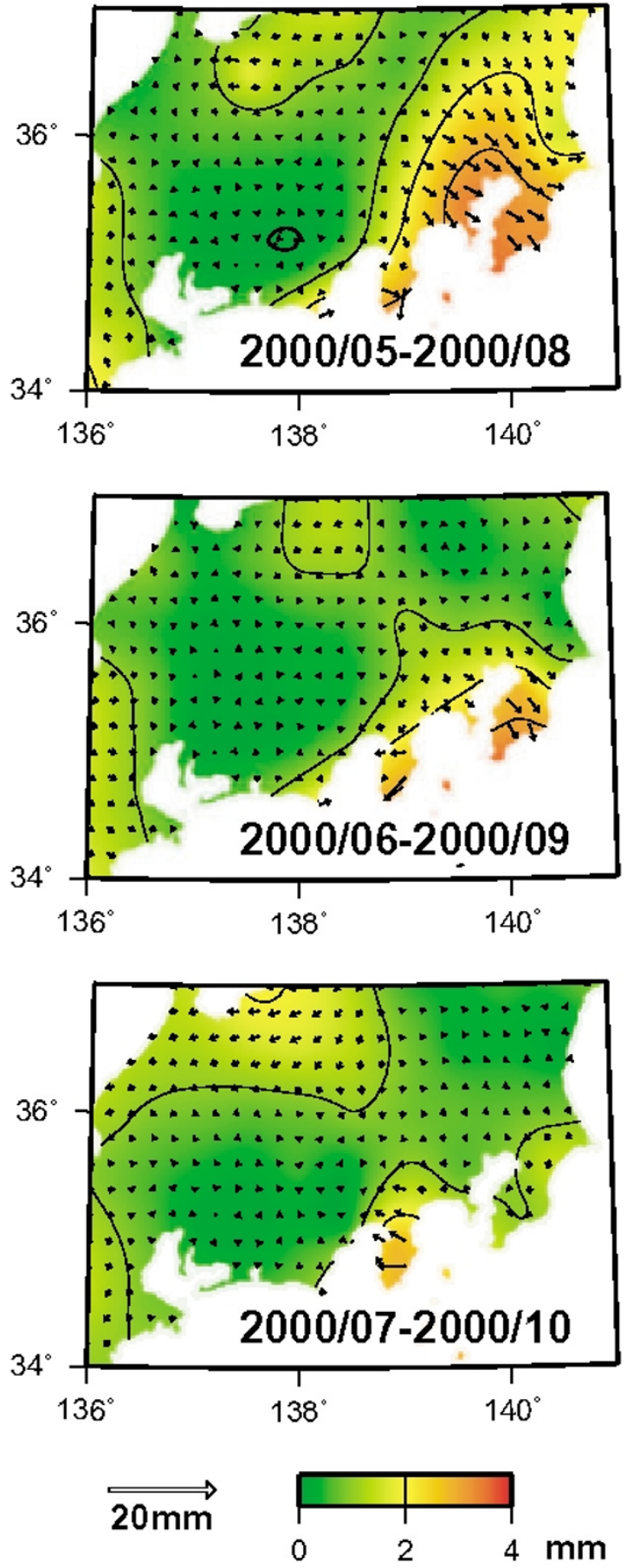

Fig. 8. Difference between the observed displacement field and the displacement calculated from the new model that takes into consideration the 'slips' shown in Fig. 7. Each panel corresponds to that in Fig. 5.

pling in the Tokai region. The inversion analyses for threemonth periods during the 2000 event show that a slow slip or a temporary suspension of the plate subduction occurred first in the focal region of the anticipated Tokai earthquake. The slow slip area then migrated to the west. Finally, a forward slip, exceeding the secular convergence velocity, started on the plate interface near Lake Hamana in the fall of 2000 . We believe that the ongoing slow slip might have been caused by the 2000 northern Izu Islands event.
Acknowledgments. We are grateful to the Geographical Survey Institute (GSI) of Japan for providing the GPS data. We also appreciate the useful suggestions of Roland Burgmann and Takuya Nishimura.

\section{References}

Furuya, M., S. Okubo, W. Sun, Y. Tanaka, J. Oikawa, H. Watanabe, and T. Maekawa, Spatiotemporal Gravity Changes at Miyakejima Volcano, Japan: Caldera Collapse, Explosive Eruptions and Magma Movement, J. Geophys. Res., 108(B4), 2219, doi:10.1029/2002JB001989, 2003.

Hatanaka, Y., T. Iizuka, M. Sawada, A. Yamagiwa, Y. Kikuta, J. M. Johnson, and C. Rocken, Improvement of the Analysis Strategy of GEONET, Bull. Geograph. Surv. Inst., 49, 11-37, 2003.

Japan Meteorological Agency, Recent seismic activity in the Miyakejima and Niijima-Kozushima region, Japan-the largest earthquake swarm ever recorded, Earth Planets Space, 52, i-viii, 2000.

Kaidzu, M., Dose velocity field in 1999 really represent standard secular field?, Prog. Abst. Geod. Soc. Jpn., P-14, 2003 (in Japanese).

Kaidzu, M., T. Nishimura, M. Murakami, S. Ozawa, T. Sagiya, H. Yarai, and T. Imakiire, Crustal deformation associated with crustal activities in the northern Izu-islands area during the summer, 2000, Earth Planets Space, 52, ix-xviii, 2000.

Kobayashi, A., T. Yamamoto, H. Takayama, and A. Yoshida, Crustal deformation in the Chubu-Kanto region at and after the 2000 seismic and volcanic activity around the northern Izu islands, J. Geodetic Soc. Japan, 49, 121-133, 2003 (in Japanese with English abstract).

Matsu'ura, M. and Y. Hasegawa, A maximum likelihood approach to nonlinear inversion under constraints, Phys. Earth Planet. Inter., 47, 179187, 1987.

Miyazaki, S., Y. Hatanaka, T. Sagiya, and T. Tada, The nationwide GPS array as an Earth observation system, Bull. Geograph. Surv. Inst., 44, 11-22, 1998.

Murakami, M. and S. Miyazaki, Periodicity of strain accumulation detected by permanent GPS array: Possible relationship to seasonality of measure earthquakes' occurrence, Geophys. Res. Lett., 28, 2983-2986, 2001.

Nishimura, T., S. Ozawa, M. Murakami, T. Sagiya, T. Tada, M. Kaidzu, and M. Ukawa, Crustal deformation caused by magma migration in the northern Izu islands, Japan, Geophys. Res. Lett., 28, 3745-3748, 2001.

Ozawa, S., M. Murakami, M. Kaidzu, T. Tada, T. Sagiya, H. Hatanaka, H. Yarai, and T. Nishimura, Detection and monitoring of ongoing aseismic slip in the Tokai region, central Japan, Science, 298, 1009-1012, 2002.

Ozawa, S., S. Miyazaki, T. Nishimura, M. Murakami, M. Kaidzu, T. Imakiire, and X. Ji, Creep, dike intrusion, and magma chamber deflation model for the 2000 Miyake eruption and the Izu islands earthquakes, J. Geophys. Res., 109, B02410, doi:10.1029/2003JB00260, 2004.

Sagiya, T., Interplate coupling in the Tokai district, Central Japan, deduced from continuous GPS data, Geophys. Res. Lett., 26, 2315-2318, 1999.

Sakai, S., T. Yamada, S. Ide, M. Mochizuki, H. Shiobara, T. Urabe, N. Hirata, M. Shinohara, T. Kanazawa, A. Nishizawa, G. Fujie, and H. Mikada, Magma migration from the point of view of seismic activity in the volcanism of Miyake-jima Island in 2000, J. Geog., 110, 145-155, 2001 (in Japanese with English abstract).

Sasai, Y., M. Uyeshima, J. Zlotnicki, H. Utada, T. Kagiyama, T. Hashimoto, and Y. Takahashi, Magnetic and electric field observations during the 2000 activity of Miyake-jima volcano, Central Japan, Earth. Planet. Sci. Lett., 203, 769-777, 2002.

Savage, J. C., A dislocation model of strain accumulation and release at a subduction zone, J. Geophys. Res., 88, 4984-4996, 1983.

Wessel, P. and W. H. F. Smith, New version of the Generic Mapping Tools released, EOS Trans., AGU, 76, 329, 1995.

Yabuki, T. and M. Matsu'ura, Geodetic data inversion using a Bayesian information criterion for spatial distribution of fault slip, Geophys. $J$. Int., 109, 363-375, 1992.

Yamamoto, T., Temporal and spatial changes of annual variation pattern of GEONET coordinate data, Japan Earth and Planetary Science Joint Meeting, D58-004, 2002.

A. Kobayashi (e-mail: akobayas@mri-jma.go.jp), A. Yoshida, T. Yamamoto, and H. Takayama 